(C) 2006 IEEE. Personal use of this material is permitted. Permission from IEEE must be obtained for all other uses, in any current or future media, including reprinting/republishing this material for advertising or promotional purposes, creating new collective works, for resale or redistribution to servers or lists, or reuse of any copyrighted component of this work in other works." 


\title{
Applications of Nano- and Mesoporous Gold in Electrodes and Electrochemical Sensors
}

\author{
Michael Cortie, Abbas Maaroof, Alessia Mortari, and Richard Wuhrer \\ Institute for Nanoscale Technology, University of Technology Sydney, \\ Broadway NSW 2007, Australia \\ Email: michael.cortie@uts.edu.au
}

\begin{abstract}
A nano- or mesoporous sponge of Au is formed when the intermetallic compound $\mathrm{AuAl}_{2}$ is de-alloyed with $\mathrm{NaOH}$. The large specific surface area of the sponge, and the unique surface chemical properties of $\mathrm{Au}$ indicate that this porous material might usefully serve as an electrode in capacitive sensors or other specialized electrochemical cells. Results for some prototype sensor and energy storage systems are presented, and methods of controlling the nature of the porosity presented.
\end{abstract}

Keywords-mesoporous gold, capacitive sensor, electrochemical biosensor

\section{INTRODUCTION}

Due to its great nobility gold is one of the few metallic elements that can be prepared in a mesoporous metallic form that is stable under ambient conditions. Removal of aluminium from the intermetallic compound $\mathrm{AuAl}_{2}$ by dissolution in an alkali provides a convenient means to prepare both bulk [1] and thin film [2] samples of this mesoporous material. The resulting spongy mass is penetrated by a high density of irregularly-shaped pores of 10 to $20 \mathrm{~nm}$ diameter, and can have a specific surface area of up to $20 \mathrm{~m}^{2} / \mathrm{g}$ [3]. In its pure form the sponge is unstable at room temperature and, if dry, it slowly sinters to a more dense form. However, both the presence of residual $\mathrm{Al}_{2} \mathrm{O}_{3}$ oxide impurities on its surface and moisture seem to retard this effect. In this presentation we review and discuss the properties and possible electrochemical applications for this new material.

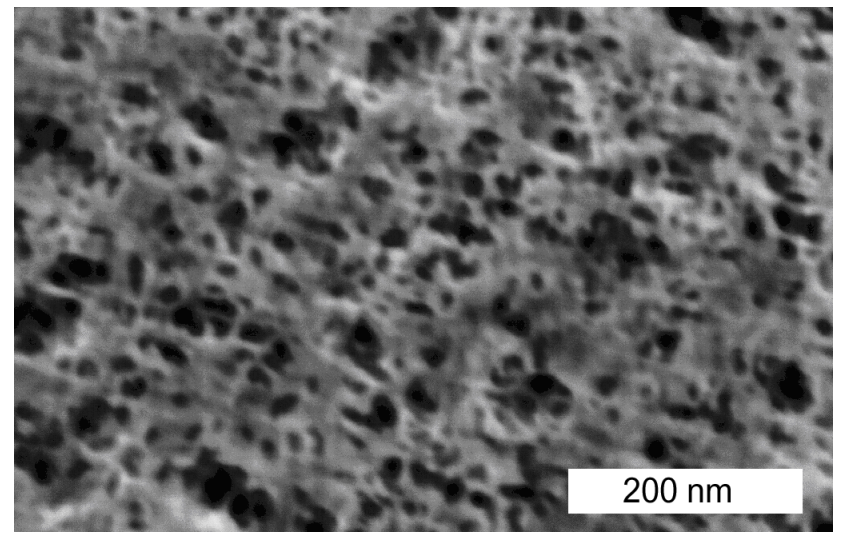

Figure 1. Example of mesoporous Au sponge produced by de-alloying $\mathrm{AuAl}_{2}$ with $\mathrm{NaOH}$. The pores are of the order of $15 \mathrm{~nm}$ diameter.

\section{EXPERIMENTAL}

Mesoporous gold films were made by de-alloying thin films of $\mathrm{AuAl}_{\mathrm{x}}$ mixtures and compounds. The starting films were prepared by co-depositing the elements using high vacuum, direct current magnetron sputtering. The sputtering targets of $\mathrm{Au}$ and $\mathrm{Al}$ were placed $150 \mathrm{~mm}$ away from the substrate. The base pressure was better than $\sim 1 \times 10^{-4} \mathrm{~Pa}$ while sputtering was carried out in the presence of flowing $\mathrm{Ar}$ at a pressure of 0.25 $\mathrm{Pa}$ with a $3 \mathrm{kV} 10 \mathrm{~W}$ radio frequency (RF) biased substrate. To ensure good homogeneity and crystallinity, the substrate could be heated to $400^{\circ} \mathrm{C}$ during deposition. After deposition the aluminium could be removed if desired from the coating by immersing the films in $0.2 \mathrm{M}$ aqueous $\mathrm{NaOH}$ solution for about one minute. The resulting coatings are neutral in colour on account of their broad and absorptive spectra characteristics[4]. De-alloyed samples were stored in Millipore water and used or characterised within two days.

\section{RESUlTS AND DISCUSSION}

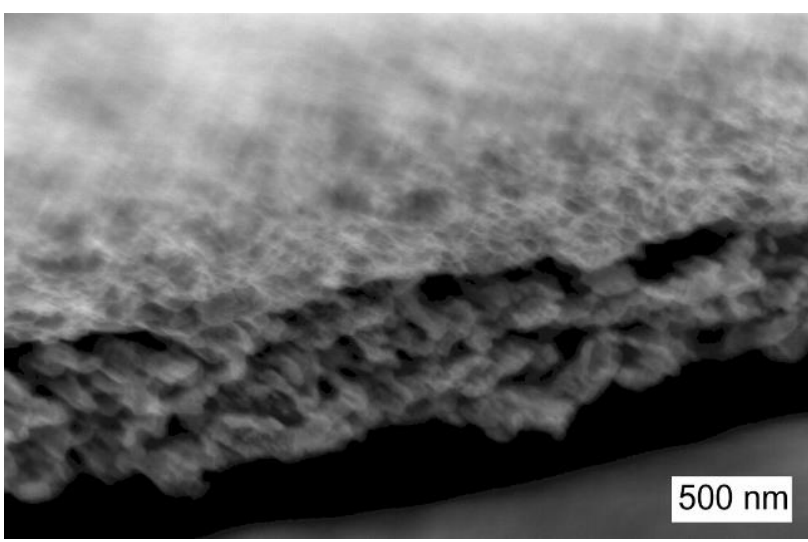

Figure 2. Cross-section of a mesoporous gold coating

The spongy nature of the mesoporous gold coatings prepared in the present work is readily apparent in Figure 2, which is a cross-section through a coating that had been deposited on a silicon wafer. Although Au only equivalent to a solid $40 \mathrm{~nm}$ thick coating had been deposited, it can be seen that the porous material resulting after de-alloying is $\sim 500 \mathrm{~nm}$ in thickness. XPS measurements (reported elsewhere[5]) 
indicate that the surfaces are of pure $\mathrm{Au}$ with negligible impurities present.

BET surface areas of up to $20 \mathrm{~m}^{2} / \mathrm{g}$ have been recorded for mesoporous $\mathrm{Au}$ [3], but the increases in electrochemical capacitance are more modest, being of the order of to 3 to 10 times that of ordinary gold coatings of the same nominal surface area[5]. Evidently, many of the pores in the gold sponge are inaccessible to ions during electrochemical measurements. Nevertheless, the increase in capacitance caused by the increased surface area has a large effect in potential step experiments, Figure 3 , in which a slow decay of a previously applied voltage may be observed.

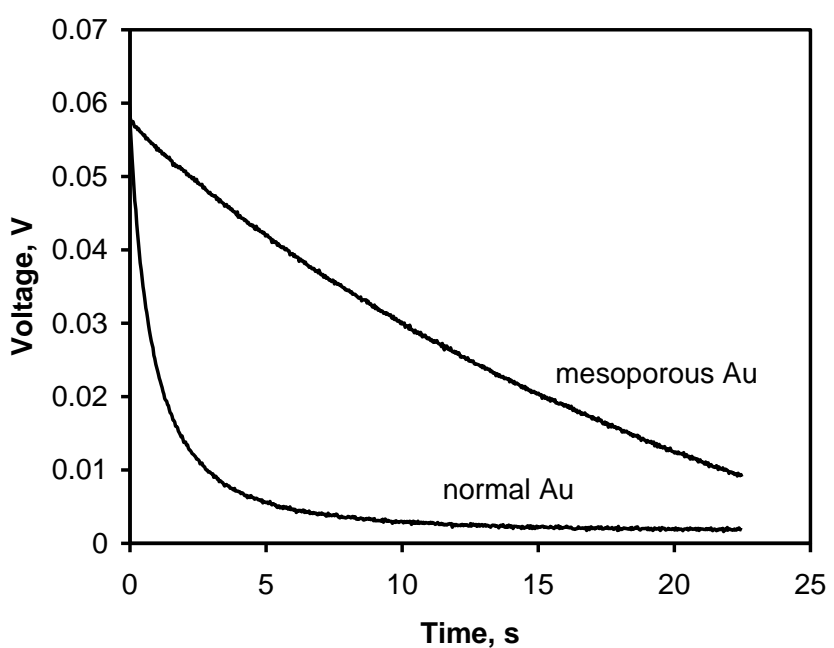

Figure 3. Potential step experiment in physiological buffer solution, showing how increased capacitance of porous gold electrode causes slower decay of voltage.

In principle, these mesoporous electrodes can be used in ultra-capacitive configurations to store energy. A prototype ultracapacitor device produced at UTS is shown in Figure 4. The energy, $U_{\mathrm{e}}$, that can be stored in such a device is given by

$$
U_{e}=\frac{C \cdot \Delta V^{2}}{2}
$$

where $C$ is the ostensible capacitance, and $\Delta V$ the voltage across the device. The quadratic dependence of $U_{\mathrm{e}}$ on $\Delta V$ means that it is essential to operate the device at the highest possible voltage. In our own work we have used an aqueous electrolyte, which unfortunately breaks down (electrolyses) at about $1.5 \mathrm{~V}$. In this case no more than $\sim 2.3 \mathrm{~mJ}$ can be stored. However, if an organic electrolyte with an operating voltage of up to $3 \mathrm{~V}$ were to be used, then it ought to be possible to store 9 $\mathrm{mJ}$ on the device shown. The other attraction of using gold in an ultracapacitor is its very high electrical conductivity. After accounting for energy lost to internal heating, the peak power that can be drawn from an ultra-capacitor while discharging it from voltage $V_{0}$ to $1 / 2 V_{0}$ is given by [6]:

$$
P=\frac{9}{16}\left(1-E_{f}\right) \frac{V_{0}^{2}}{R}
$$

where $P$ is the power drawn from the ultra-capacitor, $E_{\mathrm{f}}$ is the discharge efficiency (i.e. if $E_{\mathrm{f}}=0.8$ then 0.2 or $20 \%$ of the energy is dissipated as heat), and $R$ is the internal resistance. Note that the power that can be supplied by an ultra-capacitor is inversely proportional to its internal resistance. Halving this latter figure will double the power. So, all else being equal, an ultracapacitor based on mesoporous gold electrodes would be considerably more energy efficient than a conventional one. While $\mathrm{Au}$ is probably too valuable to be used in the ultracapacitors of ordinary consumer devices, we believe that it would be feasible to use it in specialized applications.

Nevertheless, it seems more likely that the increased capacitance on offer from mesoporous gold could be more profitably used in capacitive sensors and biosensors of various types. Gold itself is an attractive material for the electrodes of such systems due primarily to the surface chemical attributes of that element which make it convenient platform for the attachment of proteins and other biological molecules. The chief advantage offered by a mesoporous gold electrode is its much larger electrochemical capacitance at the same nominal surface area and gold loading. This would prolong the decay of voltage in potential step systems, which increases the log-linear range of data available for a given analogue-to-digital sampling rate and hence improves the quality of the measurement. Figure 5 shows the transducted signal from a mesoporous electrode immersed in milk. The change in capacitance due to adsorption of adventitious proteins and fats was undetectable using an ordinary gold electrode of the same nominal surface area for this combination of instrumentation and analyte, but is readily detectable for the mesoporous electrode.

Mesoporous gold electrodes can also reversibly alloy and de-alloy with lithium, and do so at low potentials, suggesting that there might be some possibilities in principle at least in respect of specialized (high voltage) lithium ion cells. The material also exhibits unusual optical properties, with a behaviour that is neither completely metallic nor dielectric [4]. Since the properties depend upon the density of pores, which can be smoothly varied in this material from none at all (solid gold) to very many (a rather fragile skeleton of highly disordered metal), it follows that its optical and electrochemical properties can be very flexible.

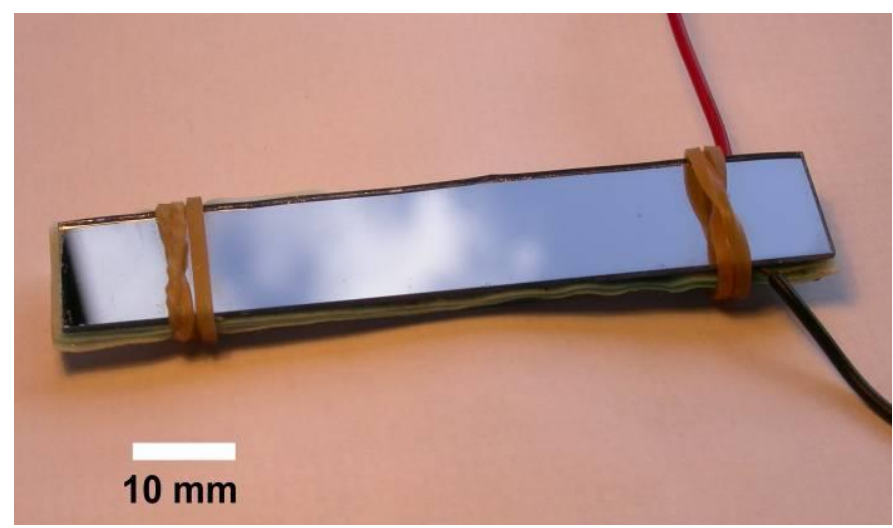

Figure 4. Prototype $1 \mathrm{mF}$ ultracapacitor based on mesoporous gold electrodes, from Cortie et al. [1] 


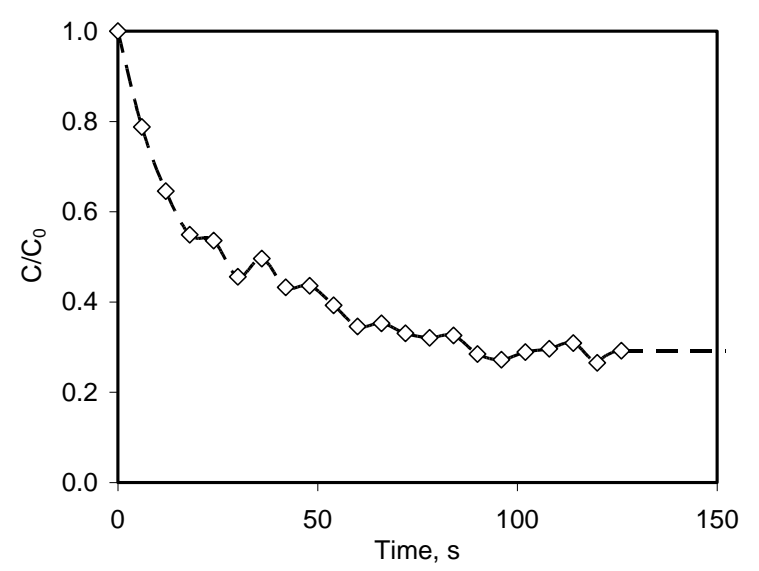

Figure 5. Rapid decrease in capacitance of mesoporous electrode explosed to pasteurized milk.

The range of morphologies available in this material may be expanded further by deliberately developing a bimodal porosity distribution in it. The key to this is to exploit the phase separation possibilities inherent in the Au-Al binary phase diagram, the relevant portion of which is shown in Figure 6. If co-deposition of the $\mathrm{Al}$ and $\mathrm{Au}$ is carried out in the two-phase region and at room temperature then the two elements form a very fine-scale mixture in the coating. In this case de-alloying produces a sponge with a relatively monodisperse pore size. In contrast, if deposition is carried out at a higher temperature, e.g. $400^{\circ} \mathrm{C}$, then phase separation of the deposit into $\mathrm{AuAl}_{2}$ and $\mathrm{Al}$ occurs. The process of phase separation can be controlled to also yield an intermediate result. This is readily evident in high resolution back scatter scanning electron microscope images, Figure 7.

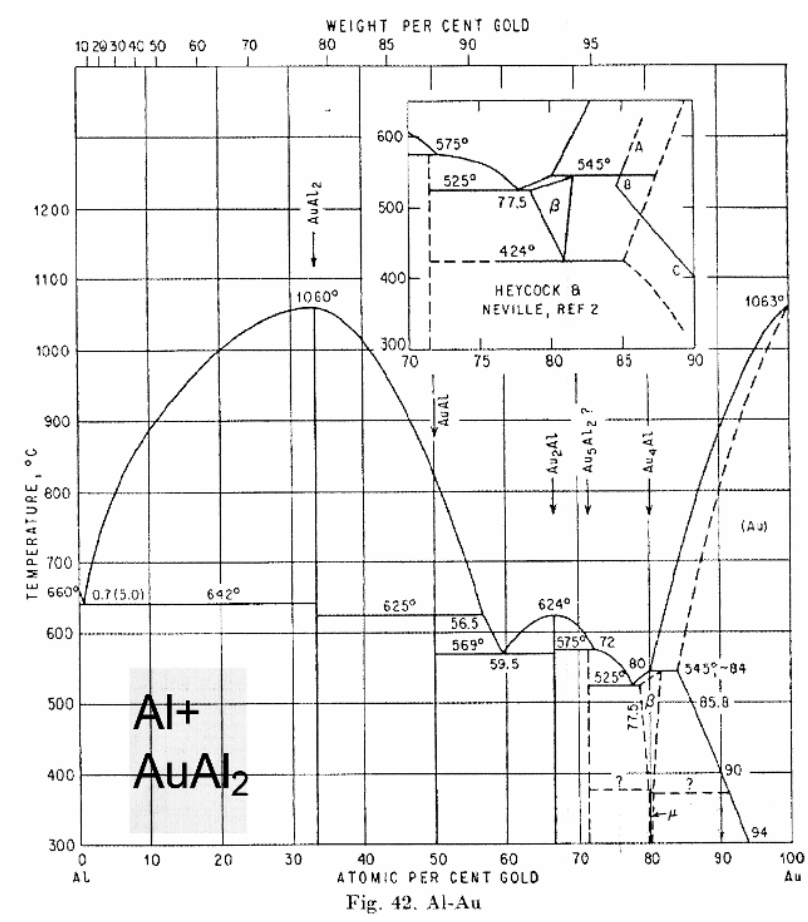

Figure 6. Al-rich end of Au-Al binary phase diagram, showing region in which well-developed two-phase microstructures are possible.

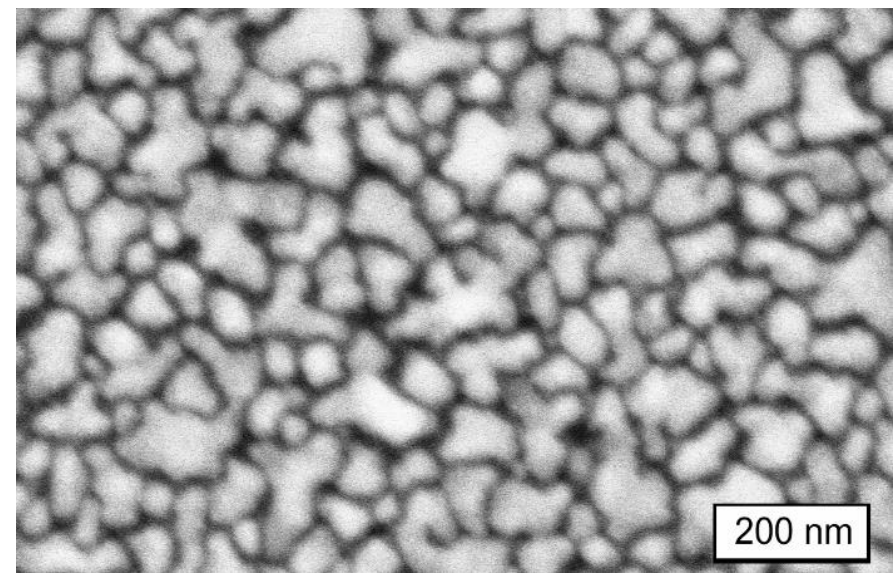

Figure 7. Two-phase microstructure of $\mathrm{AuAl}_{2}$ (light) and $\mathrm{Al}$ (dark) produced when co-depositing $40 \mathrm{~nm}$ of $\mathrm{Au}$ and $80 \mathrm{~nm}$ of $\mathrm{Al}$ at $400^{\circ} \mathrm{C}$.
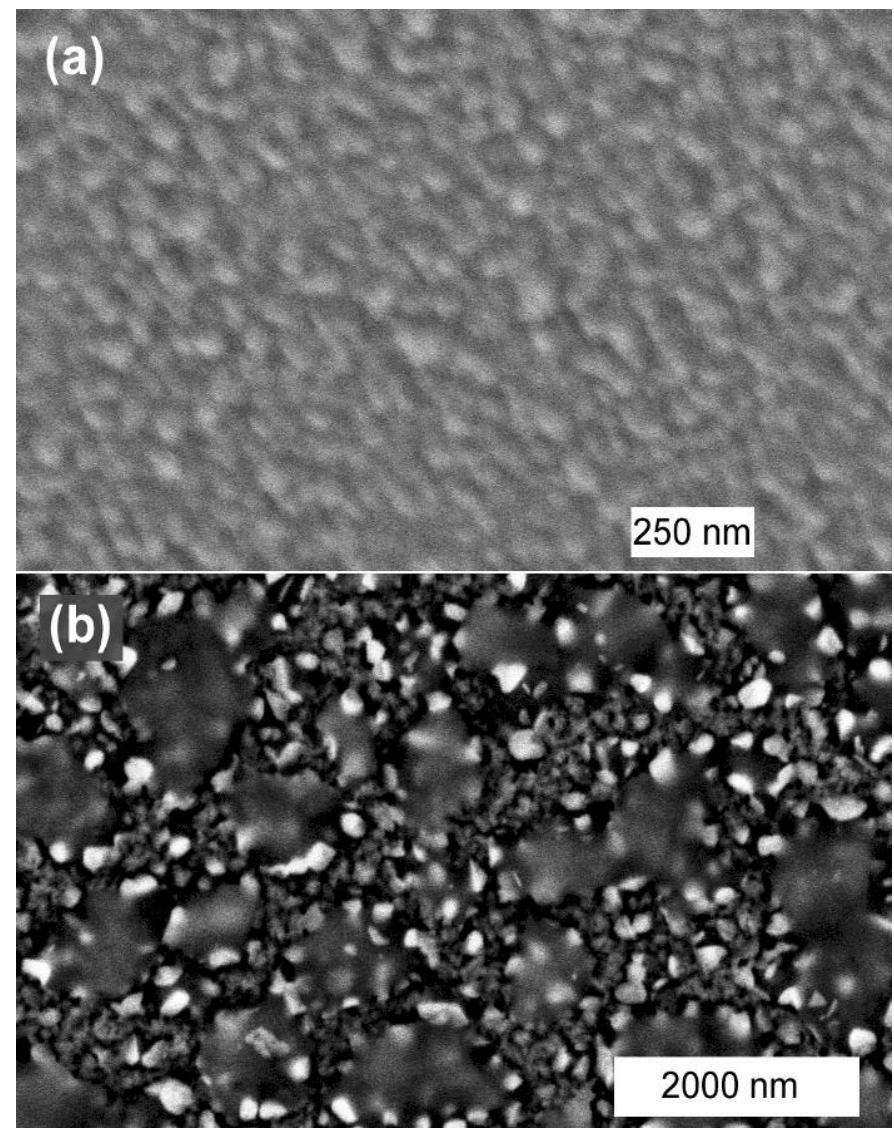

Figure 8. Effect of heat treatment on phase seperation and microstructures possible when $\mathrm{Al}$ and $\mathrm{Au}$ are co-deposited in the two-phase $\mathrm{Al}+\mathrm{AuAl}_{2}$ field.

(a) 'in lense' image of $20 \mathrm{~nm}$ Au plus $300 \mathrm{~nm} \mathrm{Al}$ deposited at room temperature, (b) 'back scatter' image $20 \mathrm{~nm}$ Au plus $300 \mathrm{~nm} \mathrm{Al}$ deposited at $400^{\circ} \mathrm{C}$ showing islands of $\mathrm{AuAl}_{2}$ (white) and $\mathrm{Al}$ (grey)

In Figure 8 we show the effect of heat treatment on the microstructures produced by co-deposition. In the case of the structure produced at room temperature no contrast was evident in electron backscatter mode, indicating that the sample was homogenous down to the nano-scale. However, the sample produced at $400^{\circ} \mathrm{C}$ contained precipitates of $\mathrm{AuAl}_{2}$, regions of 
$\mathrm{Al}$, and an intermediate duplex microstructure. When these samples are de-alloyed the regions corresponding to the $\mathrm{Al}$ phase are completely dissolved out, and manifest as channels of about $1000 \mathrm{~nm}$ diameter in the resulting sponge. In contrast the $\mathrm{AuAl}_{2}$ phase de-alloys to produce pores and channels of $\sim 15 \mathrm{~nm}$ diameter. The result is a bimodal distribution of pore sizes, which would be useful in some electrochemically-based sensor or biosensor applications since it would permit ready mass transfer of liquids through the sponge.

Further control of the morphology of the coating and hence that of the resulting sponge is possible by variation of the $\mathrm{Au}: \mathrm{Al}$ ratio, even in the absence of heat treatment. In Figure 9 it is evident that there are conditions that produce very rough coatings of the mixed $\mathrm{Al} / \mathrm{Al}$ deposit. These de-alloy to produce corresponding rough and fibrous mesoporous structures.

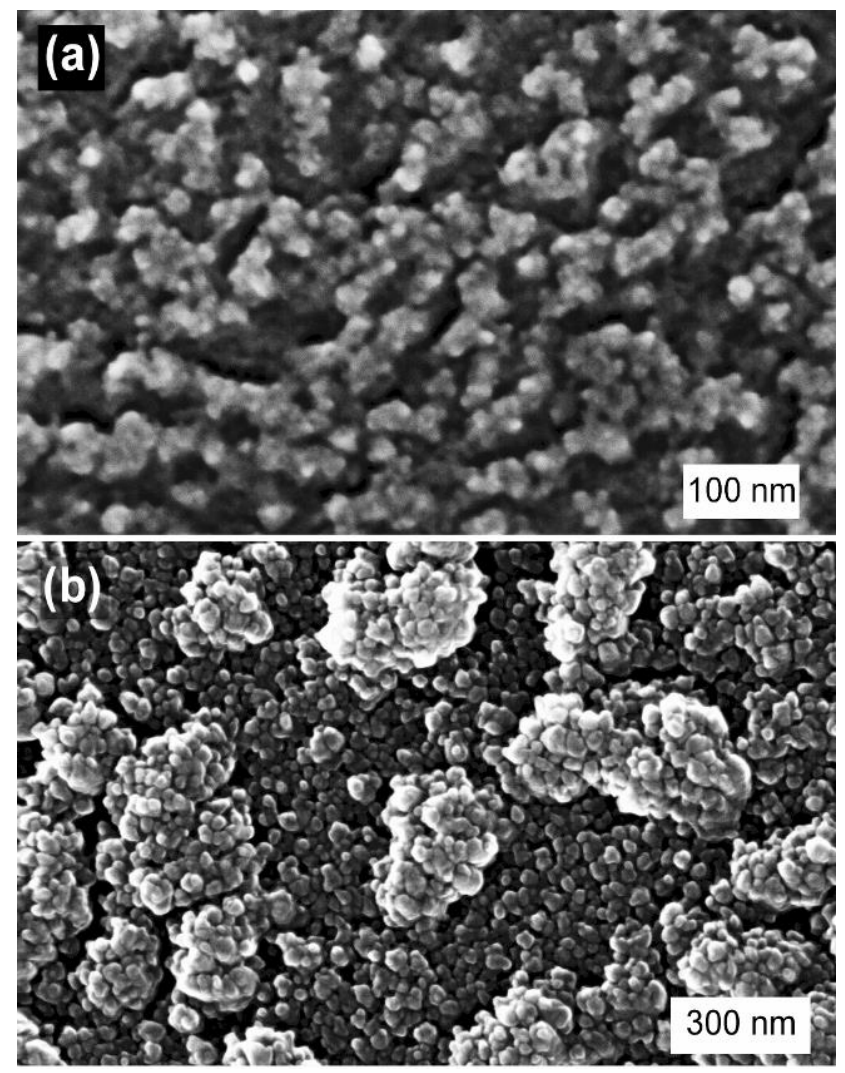

Figure 9. Rough surfaces produced when depositing Al-rich coatings at room temperature, (a) $20 \mathrm{~nm}$ Au and $500 \mathrm{~nm} \mathrm{Al}$, (b) $20 \mathrm{~nm}$ Au plus $40 \mathrm{~nm} \mathrm{Al}$.

\section{CONCLUSIONS}

Mesoporous gold has a significantly increased surface area compared to ordinary gold, and this can be exploited to give an enhanced electrochemical capacitance. Electrochemical sensors based on this material can exhibit an enhanced accuracy and sensitivity, particularly if they are based on the potential step concept. The morphology of the porosity can be modified by control of the microstructure. In particular, the deliberate development of fine scale $\mathrm{Al}+\mathrm{AuAl}_{2}$ structures can be used to produce a bimodal distribution in pore sizes.

\section{ACKNOWLEDGMENT}

The authors thank the World Gold Council and University of Technology Sydney for financial support.

\section{REFERENCES}

[1] M. B. Cortie, A. I. Maaroof, and G. B. Smith, "Electrochemical capacitance of mesoporous gold", Gold Bulletin, vol. 38, pp.15-23, 2005.

[2] M. B. Cortie, A. Maaroof, G. B. Smith, and P. Ngoepe, "Nanoscale coatings of $\mathrm{AuAl}_{\mathrm{x}}$ and $\mathrm{PtAl}_{\mathrm{x}}$ and their mesoporous elemental derivatives", Current Applied Physics, vol. 6, pp.440-443, 2006.

[3] L. Glaner, E. van der Lingen, and M. B. Cortie, "Gold catalysts and methods for their preparation", Australian Patent, 2003/215039,

[4] A. I. Maaroof, M. B. Cortie, and G. B. Smith, "Optical properties of mesoporous gold films", Journal of Applied Optics A: Pure and Applied Optics, vol. 7, pp.303-309, 2005.

[5] A. Mortari, A. Maaroof, D. Martin, and M. B. Cortie, "Mesoporous gold electrodes for measurement of electrolytic double layer capacitance", Sensors and Actuators B, vol., pp.in press, 2006.

[6] A. Burke, "Ultracapacitors: why, how, and where is the technology?" Journal of Power Souces, vol. 91, pp.3750,2000 . 